\title{
ASSOCIATION OF APGAR SCORE WITH DELIVERY MODE IN THE NON DISTRESS NEWBORNS
}

\author{
${ }^{1}$ Karamatollah Rahmanian, ${ }^{1}$ Abdolreza Sotoodeh Jahromi, \\ ${ }^{2}$ Vajihe Rahmanian, ${ }^{2}$ Mitra Ghasvari and ${ }^{2,3}$ PardisForooghi Abari \\ ${ }^{1}$ Research Center for Social Determinants of Health, Jahrom University of Medical Sciences, Jahrom, Iran \\ ${ }^{2}$ Department of Statistical, Jahrom University of Medical Sciences, Jahrom, Iran and \\ Statistical Unit, Jahrom University of Medical Sciences, Jahrom, Iran \\ ${ }^{3}$ Student Research Committeer, Jahrom University of Medical Sciences, Jahrom, Iran
}

Received 2013-12-21; Revised 2013-12-26; Accepted 2013-12-28

\begin{abstract}
The Apgar score is the most commonly used measure of newborn infant well-being. Infants of women with caesarean section were at increased risk of low Apgar score and/or perinatal death. The aim of study was to determine the impact of the cesarean section on Apgare score. This is a case-control study, which compared 100 Elective Cesarean Section (ECS) cases, with 199 uncomplicated Normal Vaginal Deliveries (NVD). All newborns were product of first or second pregnancy and they are full term and singleton babies. Apgar score in the minute 5 was measured in both groups. The descriptive and analytical statistics $\left(\mathrm{X}^{2}\right.$ and $\mathrm{T}$ test) were used. Average of fifth Apgarscore was $8.63 \pm 0.79$ in NVD group and was $8.79 \pm 0.94$ in ECS group, that there was no significant difference. About $76.5 \%$ of the NVD neonates in minute 5 had Apgar scores of 9 and 10. While in cesarean group, 59\% of the neonates in minute 5 had Apgar scores of 9 and 10. There was no significant difference between minute five Apgar scores of the two groups. Therefore it is not acceptable that with ECS baby will have worse Apgar score.
\end{abstract}

Keywords: Apgar Score, Newborn, Cesarean, Delivery

\section{INTRODUCTION}

Newborn infants should assess immediately after delivery. The Apgar score is a simple and effective method for assessing of the neonatal healthin the immediate period after birth (Apgar et al., 1958; Papile, 2001). The Apgar score includes five components: Appearance, pulse, grimace, activity and respiration, each of the five clinical findings is assessed a value of 0 to 2 . This score is the sum of the five components (Apgar et al., 1958). A low 5 min Apgar score is a valid predictor of neonatal mortality, neurologic disability, central auditory impairment and lower intelligence quotient (Nelson and Ellenberg, 1981; Drage et al., 1964; Odd et al., 2008a; Moster et al., 2001; Lee et al., 2010; Jiang and Wilkinson, 2006; AAP, 2006). Also Casey et al. (2001) reported that the mortality risk was very higher for newborn with score $\leq 3$ than newborn with score $\geq 7$. Previous works showed that many factors such as social class, educational level, social factors, maternal diseases, fetal factors and others affected on newborn Apgarscores (Hemminki et al., 1990; Kalland et al., 2006; Odd et al., 2008b). Also, Suka et al. (2002) suggested that the preeclampsia was more frequently associated to low Apgarscore.

Vaginal delivery causes lung clearance from secretions and fluids with pressure on neonate chest. This phenomena help to neonate for better respiration. Cesarean section is an alternative method of delivery in conditions that threatened fetal and maternal life (Levine et al., 2001; Zanardo et al., 2004; Villar et al., 2007; Robson, 2001). But today, some mothers select cesarean section for fear of vaginal delivery pain and offspring protection. Drugs used for anesthesia during cesarean section can decrease uterine and placental Center for Social Determinants of Health, Jahrom University of Medical Sciences, Jahrom, Iran 
circulation then it causes fetal hypoxemia (Miller et al., 2000). Near $32 \%$ of infants born by cesarean section during 2008 in Jahrom (Rahmanian et al., 2011), especially due to previous cesarean section (35\%). Some of studies showed that the mean Apgar score of 5 min in vaginally delivered newborn was higher than in those delivered by cesarean section (Rafati et al., 2006; Garzoli et al., 2007). Also, in a study conducted by Carlsson-Wallin et al. (2010) infants of women with one previous cesarean section were at increased risk of low Apgar score compared with infants of women with one previous vaginal delivery (Carlsson-Wallin et al., 2010). But other researchers suggested that Apgar score was not associated to mode of delivery (Ziae and Fallah, 2008; Kalos et al., 2006; Kilsztajn et al., 2007; Burt et al., 1988; Islami and Fallah, 2008).

According to opposite results of these investigates, the aim of this study was to assess the relation of Apgarscore at $5 \mathrm{~min}$ and delivery mode in elective cesarean section and normal vaginal delivery.

\section{MATERIALS AND METHODS}

The fifth minute Apgarscore recorded on the birth documentation was used as ameasure of infant health at birth. A case-control study of Apgar score was conducted in all full term (gestational age 37 weeks or higher) and singleton deliveries between March 21, 2008 and March 20, 2009 at two hospitals, which has situated in Jahrom, southern of Iran. We reviewed one year delivery records and record first and second uncomplicated deliveries. Among them, there were 100 cases of elective cesarean section (case group). For each of the cases, two newborns that delivered vaginally were randomly selected as control group. Data has been collected through a questionnaire included delivery route, $5 \mathrm{~min}$ Apgar score, birth weight, sex of neonate, gestational age at delivery, gravid, medical complications (hypertension, diabetes, asthma, cardiac disease, renal disease) and instrumental use at delivery. Apgar score divided to three groups, 5-6, 7-8 and score 910. Also birth weight divided to two groups, normal birth weight $(\geq 2500 \mathrm{gm})$ and low birth weight $(<2500 \mathrm{gm})$. Exclusion criteria included any medical complications of mother during pregnancy and delivery, fetal distress and disease and use of instrument for delivery.

The data recorded by SPSS, version 11.5. The qualitative variables analyzed by descriptive and quantitative variables analyzed by mean \pm standard deviation. For relation of Apgarscore with qualitative and quantitative variables used chi square, independent $\mathrm{t}$-test and logistic regression. The $\mathrm{p}<0.05$ considered as significant.

\section{RESULTS}

Of among newborns in control group, 48.7\% were boys, compared to $46 \%$ of the newborns in case group (Table 1). About $95 \%$ of participants had normal birth weight in both studied groups.

According to Table 1, the mean Apgarscore was no significant difference in both case and control groups $(8.79 \pm 0.94$ Vs. $8.63 \pm 0.79 ; p=0.12)$.One hundred fifty two infants (76.4\%) in the NVD group had Apgar score $\geq 9$ at 5 min after birth and $59(59.0 \%)$ infants had Apgar score $\geq 9$ at $5 \mathrm{~min}$ after birth in the ECS group that was different statistically $(\mathrm{p}=0.001)$. Although, birth weight was 67 gm higher in control group than in case group but there was no significant difference $(\mathrm{p}=0.236)$.

Table 1. Characteristics of case and control groups

\begin{tabular}{|c|c|c|c|c|c|}
\hline \multirow[b]{2}{*}{$\begin{array}{l}\text { Variable } \\
\text { Qualitative }\end{array}$} & \multicolumn{2}{|c|}{$\operatorname{NVD}(\mathrm{n}=199)$} & \multicolumn{3}{|c|}{$\operatorname{ECS}(n=100)$} \\
\hline & Number & $\%$ & Number & $\%$ & $P$ value \\
\hline \multicolumn{6}{|l|}{ Sex } \\
\hline Boy & 97.00 & 48.70 & 46.00 & 46.00 & 0.654 \\
\hline girl & 102.00 & 51.30 & 54.00 & 54.00 & \\
\hline \multicolumn{6}{|c|}{ Birth weight group (gram) } \\
\hline$\geq 2500$ & 190.00 & 95.50 & 95.00 & 95.00 & 0.854 \\
\hline$<2500$ & 9.00 & 4.50 & 5.00 & 5.00 & \\
\hline \multicolumn{6}{|c|}{ Apgar score group, $5 \mathrm{~min}$} \\
\hline $5-6$ & 8.00 & 4.00 & 2.00 & 2.00 & 0.001 \\
\hline $7-8$ & 39.00 & 19.60 & 39.00 & 39.00 & \\
\hline $9-10$ & 152.00 & 76.40 & 59.00 & 59.00 & \\
\hline Quantitative & Mean & SD & Mean & SD & \\
\hline Apgar score, $5 \mathrm{~min}$ & 8.63 & 0.79 & 8.79 & 0.94 & 0.120 \\
\hline Birth weight; gram & 3219.00 & 448.60 & 3152.00 & 464.60 & 0.236 \\
\hline
\end{tabular}

Abbreviations: Elective Cesarean Section (ECS); Normal Vaginal Delivery (NVD) 
Table 2. Association of Apgar score at 5 minute after birth and mode of delivery

\begin{tabular}{llll}
\hline & Odds ratio & Confidence interval, 95\% & P value \\
\hline Apgar score, 5 min, 9-10 & 1.00 & & \\
$7-8$ & 1.55 & $1.50-4.40$ & 0.001 \\
$<7$ & 0.64 & $0.13-3.12$ & 0.585 \\
Birth weight group (gram), $\geq 2500$ & 1.00 & & \\
$<2500$ & 1.17 & $0.36-3.73$ & 0.790 \\
Sex, boy & 1.00 & $0.65-1.76$ & 0.779 \\
Girl & 1.07 & \\
\hline
\end{tabular}

Table 2 showed the relations of studied variables between the both case and control groups with logistic regression. There were no significant differences between Apgar score and delivery modes with sex and birth weight. Elective cesarean section increased about 1.55 fold risk of Apgar score 7-8 than Apgar score of $9-10(p=0.001)$.

\section{DISCUSSION}

Apgar score has been used to evaluate of newborn condition. The low Apgar score indicates the adverse state of newborn. The cesarean section seems affect and reduces the Apgarscore during $5 \mathrm{~min}$ of life. Our result showed increased risk of Apgar 7-8 in ECS group in compare to no significant difference between the mean Apgar scores in newborns delivered by normal vaginal delivery (control group) and by elective cesarean section (case group). This result reported by Kalos et al. (2006); Burt et al. (1988); Kilsztajn et al. (2007) and Eberle et al. (2006) that delivery mode don't affect on Apgar score. Also in Iran, Islami and Fallah (2008) and Sabzi et al. (2006) reported that Apgar score was no related to delivery modes. But other investigators reported that there was a relation between Apgar score and delivery modes (Garzoli et al., 2007; Murphy et al., 1984). In Iran, Rafati et al. (2006) reported that Apgar score was higher in neonates delivered vaginally than in neonates delivered by other modes. Also, Kaveh et al. (2004) suggested that acidemia associated to delivery modes and to Apgar score. Rafati et al. (2006) and Ratcliffe and Evan (1993) suggested that neonatal Apgar score in cesarean section by spinal anesthesia is higher than in the general anesthesia. The different result in studies may be due to type of study, selected infants, type of anesthesia and duration of surgery.

Our study showed that the mean Apgar score was no difference in two studied groups by gender. Also, Islami and Fallah (2008) suggested that Apgar score was no related to gender. But Kaveh et al. (2004) and Nagy et al. (2009) reported a significant relation between Apgar score and gender.

Our study had some limitations as following:
Some pregnant women maybe in early stage of disease that it can't diagnose but it can affect on fetus. Another was that we used medical records. We don't control for duration of labor.

\section{CONCLUSION}

It was not found any significantly different between the mean Apgar score at 5 min in infants after birth in women who underwent an elective cesarean section compared with those who delivered vaginally.

\section{ACKNOWLEDGEMENT}

Authors thank the participants and Jahrom University of Medical Sciences for financial supports. This article is from thesis of medical student (PardisForooghiAbari).

\section{REFERENCES}

AAP, 2006. The Apgar Score. Pediatrics, 117: 14441447. DOI: $10.1542 /$ peds.2006-0325

Apgar, V., D.A. Holaday, L.S. James and I.M. Weisbort, 1958. Evaluation of the newborn infant-second report. JAMA, 168: 1985-1988. DOI: c10.1001/jama.1958.03000150027007

Burt, R.D., T.L. Vaughan, J.R. Daling, 1988. Evaluating the risks of cesarean section: Low Apgar score in repeat C-section and vaginal deliveries. Am. J. Public Health, 78: 1312-1314. DOI: 10.2105/AJPH.78.10.1312

Carlsson-Wallin, M., P. Ekstrom, K. Marsal and K. Kallen, 2010. Apgar score and perinatal death after one previous caesarean delivery. BJOG, 117: 10881097. DOI: $10.1111 /$ j.1471-0528.2010.02614.x

Casey, B.M., D.D. McIntire and K.J. Leveno, 2001. The continuing value of the Apgar score for the assessment of newborn infants. N. Engl. J. Med., 344: 467-471. DOI: 10.1056/NEJM200102153440701 
Drage, J.S., C. Kennedy and B.K. Schwarz, 1964. The Apgar score as an index of neonatal mortality: A report from the collaborative study of cerebral palsy. Obstet. Gynecol., 24: 222-230. PMID: 14199529

Eberle, A.S., E.M. Ganem, N.S.P. Modolo, R.B. Amorim and G. Nakamura et al., 2006. The Interaction between labor analgesia and its results. Assessment Newborn's Weight and Apgar Score. Rev. Bras. Anestesiol., 56: 343-351. DOI: 10.1590/S003470942006000400002

Garzoli, E., M. Monteleone, C. Migliori and F. Abrami, 2007. Umblical acid-base status of term infants: Corelation with delivery mode. Pediatr. Med. Chir., 29: 202-205. PMID: 17715603

Hemminki, E., M. Malin and O. Rahkonen, 1990. Mother's social class and perinatal problems in a low-problem area. Int. J. Epidemiol., 19: 983-990. DOI: $10.1093 /$ ije/19.4.983

Islami, Z. and R. Fallah, 2008. Evaluation of the Apgar score and its related factors in neonates born in hospitals of Yazd. JSSU, 16: 40-45.

Jiang, Z.D. and A.R. Wilkinson, 2006. Neonatal auditory function and depressed Apgar score: Correlation of brainstem auditory response with Apgar score. Acta Paediatr., 95: 1556-1560. DOI: 10.1080/08035250600681673

Kalland, M., J. Sinkkonen, M. Gissler, J. Merilainen and M.A. Siimes, 2006. Maternal smoking behavior, background and neonatal health in Finnish children subsequently placed in foster care. Child Abuse. Negl., $\quad 30$ : 1037-1047. DOI: 10.1016/j.chiabu.2006.03.005

Kalos, T., O.D. Saugstad, A.K. Daltveit, S.T. Nilsen and P. Qian, 2006. Planned cesarean versus planned vaginal delivery at term: Comparison of newborn infant outcomes. Am. J. Obstet. Gynecol., 195: 1538-1543. DOI: 10.1016/j.ajog.2006.05.005

Kaveh, M., F. Davari and M. Farahani, 2004. Apgar score and arterial blood gas in the first hour of birth in neonates. Iran. J. Pediatr., 14: 27-32.

Kilsztajn, S., E.D.S. Lopes, M.S.N.D. Carmo and A.M.D.A. Reyes, 2007. Apgar score associated with mode of delivery in Sao Paulo State, Brazil. Cad. Saude Publica, 23: 1886-1892. PMID: 17653406

Lee, H.C., M. Subeh and J.B. Gould, 2010. Low Apgar score and mortality in extremely preterm neonates born in the United States. Acta Paediatr., 99: 17851789. DOI: $10.1111 /$ j.1651-2227.2010.01935.x
Levine, E.M., V. Ghai, J.J. Barton and C.M. Strom, 2001. Mode of delivery and risk of respiratory diseases in newborns. Obstet. Gynecol., 97: 439442. DOI: 10.1016/S0029-7844(00)01150-9

Miller, R.D., R.E. Cuchiara, E.D. Miller, M.E. Roizen and J.J. Sauarese, 2000. Anesthesia. 1st Edn., Churchill, Living Stone, USA.

Moster, D., R.T. Lie, L.M. Irgens, T. Bjerkedal and T. Markestad, 2001. The association of Apgar score with subsequent death and cerebral palsy: A population-based study in term infants. J. Pediatr., 138: 798-803. DOI: 10.1067/mpd.2001.114694

Murphy, J.F., M. Dauncey, G.A.D. Rees, M. Rosen and O.P. Gray, 1984. Obstetric analgesia, anasthesia and the Apgar score. Anaesthesia, 39: 760-763. DOI: 10.1111/j.1365-2044.1984.tb06518.x

Nagy, E., H. Orvos, J. Bakki and A. Pal, 2009. Sexdifferences in Apgar scores for full-term neonates. Acta Paediatr., 98: 897-900. DOI: 10.1111/j.16512227.2009.01238.x

Nelson, K.B. and J.H. Ellenberg, 1981. Apgar scores as predictors of chronic neurologic disability. Pediatrics, 68: 36-44. PMID: 7243507

Odd, D.E., F. Rasmussen, D. Gunnell, G. Lewis and A. Whitelaw, 2008a. A cohort study of low Apgar scores and cognitive outcomes. Arch. Dis. Child Fetal. Neonatal. Ed., 93: F115-F120. DOI: 10.1136/adc.2007.123745

Odd, D.E., P. Doyle, D. Gunnell, G. Lewis and A. Whitelaw et al., 2008b. Risk of low Apgar score and socioeconomic position: A study of Swedish male births. Acta Paediatr., 97: 1275-1280. DOI: 10.1111/j.1651-2227.2008.00862.x

Papile, L.A., 2001. The Apgar score in the 21st century. N. Engl. J. Med., 344: 519-520. DOI: 10.1056/NEJM200102153440709

Rafati, S., B. Hajie, F. HajEbrahim-Tehrani, M.R. Jalali-Nodooshen and M.H. Mozafari et al., 2006. Neonatal Apgar scores and umbilical blood gas changes in vaginal delivery and cesarean: A comparative study. Tehran Univ. Med. J., 64: 6168.

Rahmanian, K., M. Ghasvari and V. Rahmanian, 2011. Cesarean, ever to need attention: Prevalence and causes of cesarean section in Jahrom, 1387. J. Jahrom Med. School, 9: 46-52. 
Ratcliffe, F.M. and J.M. Evans, 1993. Neonatal wellbeing after elective caesarean delivery with general, spinal, epidural anesthesia. Eur. J. Anesthesiol., 10: 175-181. PMID: 8495679

Robson, M.S., 2001. Can we reduce the caesarean section rate? Best Pract. Res. Clin. Obstet. Gynaecol., 15: 179-194. DOI: 10.1053/beog.2000.0156

Sabzi, F., H. Teymouri, F. Nematollahi, 2006. Comparison of Apgar score of the minute 5 and 10 of neonates borne by painless delivery (iv sedation) and cesarean section. Yafteh, 8: 67-72.

Suka, M., H. Sugimori, M. Nakamura, K. Haginiwa and K. Yoshida, 2002. Risk factors of low APGAR score in japanese full-term deliveries: A case-control study. J. Epidemiol., 12: 320-323. DOI: $10.2188 /$ jea. 12.320
Villar, J., G. Carroli, N. Zavaleta, A. Donner and D. Wojdyla et al., 2007. Maternal and neonatal individual risks and benefits associated with caesarean delivery: Multicentre prospective study. Br. Med. J., 335: 1025. DOI: 10.1136/bmj.39363.706956.55

Zanardo, V., A.K. Simbi, M. Franzoi, G. Solda and A. Salvadori et al., 2004. Neonatal respiratory morbidity risk and mode of delivery at term: Influence of timing of elective caesarean delivery. Acta Paediatr., 93: 643-647. DOI: 10.1111/j.16512227.2004.tb02990.x

Ziae, S. and R. Fallah, 2008. APGAR score and effective factors in newbornes delivered in Yazd hospitals. J. Shahid Sadooghi, 16: 40-45. 